\title{
Bacillus cytotoxicus Genomics: Chromosomal Diversity and Plasmidome Versatility
}

\author{
Nancy Fayad ${ }^{1,2 \dagger}$, Klèma Marcel Koné ${ }^{1 \dagger}$, Annika Gillis ${ }^{1}$ and Jacques Mahillon ${ }^{1 *}$ \\ ${ }^{1}$ Laboratory of Food and Environmental Microbiology, Earth and Life Institute, Louvain-la-Neuve, Belgium, \\ ${ }^{2}$ School of Pharmacy, Lebanese American University, Byblos, Lebanon
}

\section{OPEN ACCESS}

Edited by:

David W. Ussery,

University of Arkansas for Medical

Sciences, United States

Reviewed by:

Xavier Bellanger,

Université de Lorraine, France

Víctor González,

National Autonomous University of

Mexico, Mexico

*Correspondence:

Jacques Mahillon

jacques.mahillon@uclouvain.be

tThese authors have contributed equally to this work

Specialty section:

This article was submitted to

Evolutionary and Genomic

Microbiology,

a section of the journal

Frontiers in Microbiology

Received: 05 October 2021

Accepted: 17 November 2021

Published: 09 December 2021

Citation:

Fayad N, Koné KM, Gillis A and Mahillon J (2021) Bacillus cytotoxicus

Genomics: Chromosomal Diversity and Plasmidome Versatility.

Front. Microbiol. 12:789929.

doi: 10.3389/fmicb.2021.789929
Bacillus cytotoxicus is the thermotolerant representative of the Bacillus cereus group. This group, also known as $B$. cereus sensu lato, comprises both beneficial and pathogenic members and includes psychrotolerant and thermotolerant species. Bacillus cytotoxicus was originally recovered from a fatal outbreak in France in 1998. This species forms a remote cluster from the $B$. cereus group members and reliably contains the cytk-1 gene, coding for a cytotoxic variant of cytotoxin $\mathrm{K}$. Although this species was originally thought to be homogenous, intra-species diversity has been recently described with four clades, six random amplified polymorphic DNA (RAPD) patterns, and 11 plasmids profiles. This study aimed to get new insights into the genomic diversity of $B$. cytotoxicus and to decipher the underlying chromosomal and plasmidial variations among six representative isolates through whole genome sequencing (WGS). Among the six sequenced strains, four fitted the previously described genomic clades $A$ and $D$, while the remaining two constituted new distinct branches. As for the plasmid content of these strains, three large plasmids were putatively conjugative and three small ones potentially mobilizable, harboring coding genes for putative leaderless bacteriocins. Mobile genetic elements, such as prophages, Insertion Sequences (IS), and Bacillus cereus repeats (bcr) greatly contributed to the $B$. cytotoxicus diversity. As for IS elements and bcr, IS3 and bcr1 were the most abundant elements and, along with the group II intron B.c.18, were found in all analyzed B. cytotoxicus strains. When compared to other B. cytotoxicus strains, the type-strain NVH 391-98 displayed a relatively low number of IS. Our results shed new light on the contribution of mobile genetic elements to the genome plasticity of $B$. cytotoxicus and their potential role in horizontal gene transfer.

Keywords: Bacillus cereus, Bacillus cytotoxicus, conjugation, mobile genetic elements, plasmid

\section{INTRODUCTION}

Bacillus cereus group, also named B. cereus sensu lato (s.l.), contains closely related Grampositive, facultative aerobe, and endospore-forming bacteria. It includes B. cereus sensu stricto (s.s.), Bacillus thuringiensis, Bacillus anthracis, Bacillus mycoides, Bacillus pseudomycoides, Bacillus weihenstephanensis, and Bacillus cytotoxicus. Recently though, more species have been proposed as new members, such as Bacillus toyonensis (Jimenez et al., 2013), Bacillus wiedmannii 
(Miller et al., 2016), Bacillus gaemokensis (Jung et al., 2010), Bacillus bingmayongensis (Liu et al., 2014), or Bacillus manliponensis (Jung et al., 2011). The group gathers member species from various ecological niches that display a large spectrum of virulence, from the insect pathogen B. thuringiensis, used worldwide as biopesticide and plant protection agent, to human pathogenic strains of $B$. anthracis or emetic B. cereus (Agata et al., 1995; Turnbull, 1999). It also spans from psychrotrophic (growth at temperature below $7^{\circ} \mathrm{C}$ ) to thermotolerant (growth up to $53^{\circ} \mathrm{C}$ ) strains (Stenfors Arnesen et al., 2008).

Some strains of B. cereus s.l. have been implicated in food outbreaks associated with emetic or diarrheic syndromes. The former is due to cereulide, a thermostable, protease and $\mathrm{pH}$-resistant dodecadepsipeptide toxin preformed in food, whose genetic determinants are plasmid-borne (Agata et al., 1994; Ehling-Schulz et al., 2004; Hoton et al., 2005). The diarrheal syndrome is presumably caused by one or more potential enterotoxins. In fact, B. cereus can produce several potential enterotoxins, including hemolysin BL (HBL), non-hemolytic enterotoxin (Nhe), enterotoxin FM (EntFM), and cytotoxin K (CytK) (Granum, 1994; Lund et al., 2000; Senesi and Ghelardi, 2010). The latter was originally discovered in a $B$. cereus strain (NVH 391-98) isolated from an outbreak that caused the death to three elderly persons in France in 1998 (Lund et al., 2000). This strain was further shown to be able to grow up to $53^{\circ} \mathrm{C}$. The name B. cytotoxicus was coined for this new thermotolerant " $B$. cereus" strain (Guinebretière et al., 2013). Due to their ability to thrive at relatively high temperatures, strains of B. cytotoxicus have recently been isolated in geothermal waters (Cavello et al., 2020). Some B. cytotoxicus isolates, including strain NVH 391-98, were shown to over-produce the CytK toxin, as compared to other strains of the same species (Heini et al., 2018). Two variants of cytotoxin $K$ have now been described: CytK-1 and CytK-2. The former is associated with B. cytotoxicus and is more cytotoxic than the second, which is found in some mesophilic strains of B. cereus (Fagerlund et al., 2004).

Bacillus cereus members have been classified into seven phylogenetic groups according to pan $C$ typing. All emetic $B$. cereus and thermotolerant $B$. cytotoxicus strains fall in groups III and VII, respectively (Guinebretière et al., 2008). These seven groups can also be organized in three genomic clades based on their core and pan-genomes. Interestingly though, the B. cytotoxicus strains form a distinct cluster among the B. cereus members (Fagerlund et al., 2007; Auger et al., 2008; Guinebretière et al., 2008; Bazinet, 2017). This B. cytotoxicus diversity was further supported in recent studies in which isolated strains were classified into four genomic clades (A-D; Stevens et al., 2019). Also, a set of strains isolated from food products were classified into six random amplified polymorphic DNA (RAPD) groups and 11 plasmid profiles (Koné et al., 2019). Although the diversity within the B. cytotoxicus species is now well established, the extent of these genetic and genomic variations remains poorly characterized. The aim of this study was to further explore the genomic and genetic diversity of six B. cytotoxicus strains pertaining to different genetic profiles.
Whole genome sequences of these strains were compared to those of other B. cytotoxicus genomes publicly available. Sequences of chromosomal indels, mobile elements, and extrachromosomal molecules were also analyzed in detail.

\section{MATERIALS AND METHODS}

\section{Strains and Genomes}

The strains used in this study for whole genome sequencing (WGS) originated from either potato flakes (E8.1, E17.4, E28.3, and PDT2.12) or instant soup (SM1.1 and SM2.8). They were selected according to their RAPD pattern, plasmid profile, and origin, as previously described (Koné et al., 2019). The genome sequences of strains NVH 391-98 (BioProject: PRJNA13624; Lapidus et al., 2008), CH_1 and CH_2 (BioProject: PRJNA394959; Stevens et al., 2019), and AFSSA_08CEB44bac (BioProject: PRJEB14962) were used as representatives of clades A, B, C, and $D$, respectively. The nucleotides sequences of these strains were retrieved from NCBI genome Refseq database. ${ }^{1}$ Although more genomes are publicly available, only one representative of each clade was retrieved for the analysis. The relevant features of the B. cytotoxicus strains used in this study are shown in Table 1.

\section{DNA Extraction and WGS}

A single fresh colony from a LB agar plate incubated at $30^{\circ} \mathrm{C}$ was cultured overnight in liquid LB medium $\left(120 \mathrm{rpm}\right.$ at $\left.30^{\circ} \mathrm{C}\right)$. Genomic DNA extraction was performed using the Wizard Genomic DNA purification kit (Promega, United States). The quality of the DNA extraction was checked with the spectrophotometer Nanodrop 1000 (ThermoFisher Scientific, Wilmington, DE, United States) and on $0.8 \%$ agarose gel electrophoresis.

The complete genomes of isolates SM2.8 and E28.3 were first sequenced by Illumina Miseq (Illumina, San Diego, CA, United States), with paired-end run $(2 \times 300 \mathrm{pb})$, followed by MinION technology sequencing (Oxford Nanopore, United Kingdom). For Illumina sequencing, a de novo assembly was conducted with SPAdes assembler software v3.10.1 (Bankevich et al., 2012) followed by a mapping with BWA-MEM version 0.7.12-r1039. ${ }^{2}$ SPAdes 3.13.0 software was then used to combine the Illumina and MinION data (Antipov et al., 2015). The demultiplexing and adapter sequence trimming were performed with Porechop v0.2.4. ${ }^{3}$ Isolates E8.1, E17.4, PDT2.12, and SM1.1 were first sequenced using PacBio (Pacific Biosciences, CA, United States) and polished with Miseq technology sequencing. Reads were de novo assembled with Fly 2.6 software (Kolmogorov et al., 2019). For polishing, paired-end sequences were trimmed with BBDuk ${ }^{4}$ and assembled with SPAdes-3.13.0 (Antipov et al., 2015). Newly sequenced genomes completeness was assessed

\footnotetext{
${ }^{1}$ https://www.ncbi.nlm.nih.gov/genome/genomes/2491?

${ }^{2} \mathrm{http}$ ///bio-bwa.sourceforge.net

${ }^{3}$ https://github.com/rrwick/Porechop

${ }^{4}$ https://sourceforge.net/projects/bbmap/
} 
TABLE 1 | Origin and main features of the Bacillus cytotoxicus strains used in this study.

\begin{tabular}{|c|c|c|c|}
\hline Strains & RAPD/plasmid profiles ${ }^{a}$ & Origin & Reference \\
\hline E8.1 & A/PP10 & Potato flake & Koné et al., 2019 \\
\hline E17.4 & E/PP2 & Potato flake & \\
\hline E28.3 & A/PP8 & Potato flake & \\
\hline PDT2.12 & F/PP4 & Potato flake & \\
\hline SM1.1 & D/PP9 & Instant soup & \\
\hline SM2.8 & D/PP2 & Instant soup & \\
\hline \multicolumn{4}{|c|}{ Genomes of representative strains retrieved from GenBank } \\
\hline Strains & Genomic clade $^{\mathrm{b}}$ & Origin & Reference \\
\hline NVH 391-98 & A & Vegetable soup & $\begin{array}{l}\text { Lapidus et al., 2008; Guinebretière et al., } \\
2013\end{array}$ \\
\hline $\mathrm{CH}_{-} 1$ & $\mathrm{~B}$ & Potato flake & Stevens et al., 2019 \\
\hline $\mathrm{CH} \_2$ & $\mathrm{C}$ & Potato flake & \\
\hline AFSSA_08CEB44Bac44 & $D$ & Semolina & BioProject: PRJEB14962 \\
\hline
\end{tabular}

According to Koné et al. (2019)a and Stevens et al. (2019). ${ }^{b}$

using Benchmarking Universal Single-Copy Orthologs (BUSCO; Seppey et al., 2019).

On average per genome, read depth ranged between 64 and 187, with read lengths N50/N90 between 9718/7246 and 16537/8431. According to BUSCO v5.0 genome completeness assessment, E17.4 and E8.1 showed coverage scores of 98.68 and $99.76 \%$, respectively, while the remaining four strains showed coverage scores of $100 \%$. Genomes were then annotated using Rapid Annotations using Subsystems Technology (RAST) web-based tool (Aziz et al., 2008). The genome sequences and annotation for the six B. cytotoxicus strains sequenced in this work have been deposited at NCBI under BioProject number PRJNA684687.

\section{Bacterial Conjugation}

As potentially conjugative plasmids were found in the $B$. cytotoxicus E8.1 and E28.3 strains (see below), a filter-mating conjugation was performed to assess their self-transferability. Bacillus cytotoxicus strains carrying the putative conjugative plasmids were used as donors (E8.1 for plasmids pE81-84 and pE81-53, and E28.3 for pE283-80), while strain E17.4, which did not carry those plasmids, was used as recipient. Spontaneous streptomycin-resistant mutants of the donor $\left(100 \mu \mathrm{g} \mathrm{ml}^{-1}\right)$ and rifampicin-resistant mutants $\left(50 \mu \mathrm{g} \mathrm{ml}^{-1}\right)$ of recipient strains were used in filter-mating experiments as previously described by Hinnekens et al. (2019). After the mating, 100 CFUs of the potential transconjugants were PCR-screened for the presence of the conjugative plasmids.

\section{Bioinformatic Analysis for Chromosomal and Plasmidial Diversity}

Mauve alignment software (Darling et al., 2010) was used to align newly sequenced genomes against representatives of the four clades previously described (Stevens et al., 2019). Bacillus cytotoxicus strain AFSSA_08CEB44bac was excluded from the subsequent analysis due to its incomplete genome assembly. To assess their relatedness, single nucleotide polymorphisms (SNPs) were also extracted as previously described using the web-based tools CSI Phylogeny v1.4 (Kaas et al., 2014).
Using MEGA X software (Kumar et al., 2018), the SNPs output files were used to establish a SNP-based phylo-dendrogram with 500 bootstrap replicates.

The average nucleotide identity (ANI), a measure of nucleotidelevel genomic similarity between the coding regions of two genomes, was evaluated via ANIb (ANI evaluation based on BLAST+). A total aligned nucleotides analysis was also done, using the JSpeciesWS Online Service (http://jspecies.ribohost. com/jspeciesws/\#home - Ribocon GmbH - Version: 3.7.9; last accessed: November 15, 2021; Richter et al., 2016).

Next, Blast Ring Image Generator (BRIG) software (Alikhan et al., 2011) was used to highlight the Insertions-Deletions (indels) among tested B. cytotoxicus genomes. The most different isolates, strains SM1.1 and SM2.8, as indicated by the SNP-based phylo-dendrogram (see below), were used as references. To furthermore explore the indels shown by BRIG, indels or novel regions sequences were retrieved using the web-based tool Panseq (Laing et al., 2010). These sequences were annotated with RAST web-based tool (Aziz et al., 2008). Function-based comparison functionality of RAST was also used to retrieve other functional differences between B. cytotoxicus genomes and to find out specific features, or new metabolic pathways. Plasmid sequence comparison was generated using BLAST+ executables (Camacho et al., 2009) and Easyfig software (Sullivan et al., 2011).

Prophages and transposable elements were also analyzed. PHAge Search Tool Enhanced Release (PHASTER) was used to find prophage sequences in chromosome and plasmid sequences (Arndt et al., 2016). In a given DNA region, the encoded phage-related proteins were annotated and the DNA region was hence designated as "questionable," "partial," or "intact" according to the number of phage-related proteins and the prophage with the highest number of similar proteins. As for Insertion Sequences (IS), the online tool ISsaga (Insertion Sequence semi-automatic genome annotation; Varani et al., 2011) was used to extract the copy number of complete IS elements followed by a manual verification of the results and the calculation of their percentage in each genome.

Bacillus cereus repeats (bcr) are 200-400 bp DNA fragments with complex secondary structures that are mostly 
chromosomic and specific to $B$. cereus group. Analysis of $b c r$ was done using nucleotide BLAST searches of the consensus bcr1-bcr18 (Kristoffersen et al., 2011) sequences against complete B. cytotoxicus genomes. Based on former studies (Tourasse et al., 2006; Kristoffersen et al., 2011) and our observations, the algorithm parameters for MegaBLAST (https://blast.ncbi.nlm.nih.gov/Blast.cgi; v2.8.1; Morgulis et al., 2008) were set as follows: The word size - length of a seed that allows the BLAST engine to initiate an alignment - was set at 16; the opening and extension of a gap were both set at 2; and expect range was set between 0 and 0.1 . Hits that covered at least $50 \%$ of the sequence length and had a minimum of $75 \%$ identity were considered as repeats. The same nucleotide MegaBLAST parameters were used to retrieve known group II introns from the intron database (Candales et al., 2011; http://webapps2.ucalgary.ca/ groupii/; Sept 2020) and B.th.I3 (Tourasse and Kolstø, 2008) which was absent from the mentioned database. This includes 27 elements with ORFs coding the Intron Encoded Protein (IEP) and three ORF-less elements.

Finally, potential bioactive compounds clusters were predicted with the online tool antiSmash v5.0 (https://antismash. secondarymetabolites.org/\#!/start; Blin et al., 2019).

\section{RESULTS}

In a previous study, Koné et al. (2019) classified a collection of $57 \mathrm{~B}$. cytotoxicus strains, isolated from different food products, into six RAPD patterns and 11 plasmid profiles. The six isolates used in the present study were selected on the basis of both their distinct RAPD and/or plasmid profiles. Four strains (E8.1, E17.4, E28.3, and PDT2.12) originated from potato flakes, and two (SM1.1 and SM2.8) were isolated from instant soup. As shown in Table 1, isolates sharing the same RAPD patterns (D for SM1.1 and SM2.8 and A for E8.1 and E28.3) showed different plasmid profiles. As for their plasmid profiles, PDT2.12 had a unique one, while E17.4 shared the same pattern with SM2.8 (Table 1).

As shown in Table 2, the chromosome sizes of the six strains ranged from 4,049,327 bp (E17.4) to 4,244,837 bp (SM2.8), with GC contents of 35.9-36.0\%. As expected from our previous work, all six sequenced isolates contained both small (from none to three) and/or large (from none to two) plasmids with sizes varying from 3,421 bp (pE283-3) to 83,570 bp (pE81-84). They were all circular, with the exception of pE283-14.

\section{Chromosomal Diversity}

The chromosomal sequences of the six strains were compared among themselves and with those of NVH 391-98, CH_1, CH_2, and AFSSA_08CEB44Bac44, representatives of clades A-D (Table 1), respectively (Figure 1). SNPs were extracted, with numbers ranging between a minimum of 81 (E8.1 vs. CH_2) and 11,394 (SM1.1 vs. CH_2). A noteworthy remark is that the extracted SNPs were dispersed on the chromosome, not clustered together.
Based on the number of SNPs, a phylo-dendrogram of these strains was also established (Figure 2). The SNP-based phylodendrogram showed that strains E8.1 and E28.3 clustered with clade C representatives, while E17.4 and PDT2.12 did not match the previously described clades. The remaining strains, namely the "instant soup" isolates SM1.1 and SM2.8, formed a remote cluster. Using the ANI on the chromosomal level, all pairs of genomes showed ANI values above 99\%, except the instant soup strains which had ANI values above 99\% with each other, but of $c a$. $98 \%$ with the rest of the strains. This is reflected in the phylo-dendrogram: SM1.1 and SM2.8 clustered together, but were phylogenetically distant from the rest.

Using Panseq (Laing et al., 2010), sequence variations among the different strains were retrieved using SM1.1 as reference. As shown in Figure 1, several regions displayed size variations (indicated by squared numbers). They not only included prophages (see below), but also several interesting metabolic loci, such as xylan degradation (\#1), acetoin metabolism (\#2), (lipo-)teichoic acid synthesis (\#4), or inositol degradation (\#7) absent from several strains. In addition, function-based comparison of the online tool RAST revealed that strain PDT2.12 harbors genes coding for lactose and galactose uptake and utilization (data not shown).

The analyzed genomes were also mined for potential clusters of bioactive compounds using the online tool antiSmash. Although eight clusters were predicted on the chromosomes of the six B. cytotoxicus strains alongside the reference ones NVH 391-98, CH_1, and CH_2, most had no similarity with known clusters, and hence, their existence is questionable. Nevertheless, clusters for the production of fengycin, an antimicrobial lipopeptide (Sur et al., 2018), and bacillibactin, a non-ribosomal peptide (Caulier et al., 2019), were found in all nine strains at similarities of 40 and $46 \%$, respectively. Another cluster found in all analyzed strains is that of the production of heme D1, a molecule produced via a non-ribosomal peptide synthetase/Type I PKS polyketide synthase pathway. However, the similarity with a known heme D1 cluster was only at $17 \%$.

\section{Extrachromosomal Diversity}

As for other members of the B. cereus group (Gillis et al., 2018), the strains of $B$. cytotoxicus analyzed in this study contain a noticeable number of extrachromosomal elements. As reported in Table 2, all the strains contain from 1 (E17.4 and PDT2.12) to 4 plasmids (E28.3 and SM1.1), with sizes varying from 3,421 to $83,570 \mathrm{bp}$. A list of the relevant features of these $B$. cytotoxicus plasmids can be found in Supplementary Table S1.

\section{The Small Plasmids: $3,4,12$, and $14 \mathrm{~kb}$}

Strain E28.3 contains two small Rolling-Circle Replicating (RCR) plasmids: pE283-3 (3,421 bp) has a replication (rep) gene distantly related to those of the staphylococcal plasmids pE194 and pSN2 (Lampson and Parisi, 1986), while pE283-4 (3,662 bp) contains a replicon related to that of pTX14-1 from $B$. thuringiensis sv. israelensis (Boe et al., 1991). A potential mobilization gene is also present in pE283-3 and shares similarities with the 
TABLE 2 | Genomic features of the six sequenced B. cytotoxicus strains.

\section{Strain (Clade)}

E8.1 (C)

\section{Chromosome size (bp)}

$4,132,005$

$4,049,237$

$4,198,865$
Plasmid

pE81-84

pE81-53

pE174-12

pE283-80

pE283-14

pE283-4

pE283-3
Plasmid size (bp)

83,570

53,121

11,673

79,734

14,402

3,662

3,421
Plasmid relevant features

102 CDS (54 hypothetical proteins)

Potentially conjugative

Contains a Tn7-like element

Closely related to pE283-80

Partially related to pPDT212-44 and the $67-\mathrm{kb}$ plasmid

(Figure 4)

Distantly related to pAW63 (Bacillus thuringiensis) and pXO2 (Bacillus anthracis) 63 CDS (33 hypothetical proteins)

Related to $\mathrm{pCE} 3$ from $B$. paranthracis

Partially related to $53-\mathrm{kb}$ plasmid and pBCM1301 of $B$. cereus (Figure 5)

Distantly related to the Clostridium perfringens $\mathrm{pCW} 3$ conjugation system

Conjugative: ca. $10^{-2}$ transconjugant per recipient cells (see experimental data) 26 CDS $(22$ hypothetical proteins)

Bacillus thuringiensis pGl3-like replicon

Partially related to pSM11-12b and pBC9801 (Figure 3)

Fibronectin type III domaincontaining protein 99 CDS (43 hypothetical proteins)

Potentially conjugative Contains a Tn7-like element Closely related to pE81-84 Partially related to pPDT212-44 and the $67-\mathrm{kb}$ plasmid (Figure 4)

Distantly related to pAW63 and pXO2

Linear plasmid; putative plasmidial tectivirus 10 CDS (nine hypothetical proteins)

Bacillus thuringiensis sv. israelensis pTX14-1-like replicon

No mob-like gene

Four 4 CDS (two hypothetical proteins)

Staphylococcal pE194- and pSN2-like replicon

Streptococcal pMV158-like and B. thuringiensis sv. israelensis pTX14-1-like Mob 
TABLE 2 | Continued

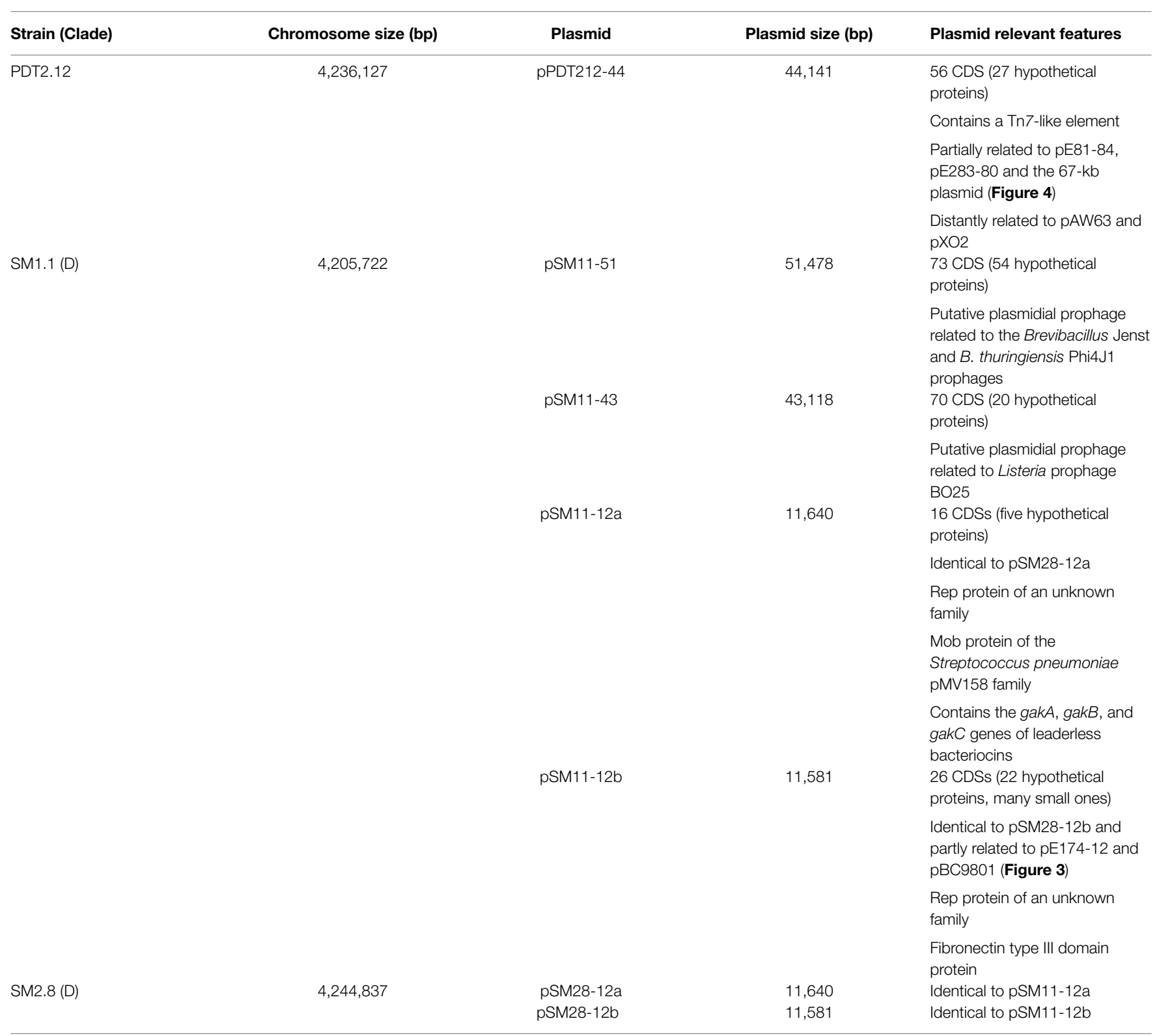

mob genes of the streptococcal pMV158 and B. thuringiensis sv. israelensis pTX14-1 plasmids (Boe et al., 1991). A third small plasmid, pE283-14, is a 14,402 bp linear molecule which is likely the prophage state of a tectivirus, as shown for related plasmidial elements found in B. thuringiensis (Gillis and Mahillon, 2014b).

Two distinct $\mathrm{ca}$. 12-kb plasmids are found in the two closely related strains SM1.1 and SM2.8. Plasmids pSM11-12a (11,640 bp) and pSM11-12b (11,581 bp) from the former strain are in fact identical to the pSM28-12a and pSM28-12b elements of the latter strain (Table 2). The most striking features of pSM11-12a/ pSM28-12a are the presence of a mobilization ( $m o b)$ gene related to that of the streptococcal pMV158 plasmid and a set of three genes coding for putative leaderless, broad spectrum bacteriocins recently described in Lactococcus garvieae and other Gram-positive bacteria, including strains of $B$. cereus (Ovchinnikov et al., 2016).

As shown in Figure 3, the pSM11-12b/pSM28-12b plasmid is related to the third $12-\mathrm{kb}$ element, pE174-12 (11,673 bp), the only extrachromosomal element of strain E17.4. However, the latter displayed a replication region unrelated to the former but homologous to the replication region of pGI3, another RCR plasmid originating from $B$. thuringiensis strain H1.1 (Hoflack et al., 1997). No other striking features could be found in $\mathrm{pE} 174-12$, except the presence of a gene coding for a putative 454-residue fibronectin type III domain containing protein (Table 2 ). These plasmids are also partially related to pBC9801 ( $a k a \mathrm{p} 7$ ), the 7-kb plasmid from $\mathrm{NVH}$ 391-98 (NC_009673.1), the reference type-strain of B. cytotoxicus (Figure 3). 
The Large Plasmids: $43,44,51,53,80$, and $84 \mathrm{~kb}$ Three of the six large plasmids found in the analyzed $B$. cytotoxicus strains are related to each other. As shown in Figure 4, the 83,570-bp plasmid pE81-84 of strain E8.1 is closely related to the slightly smaller pE283-80 (79,734 bp) from strain E28.3. They differ by a 3,836 bp segment missing in the latter and by a different location of another segment. About half of these two elements is missing in pPDT212-44 (44,141 bp), the only plasmid of the more distantly related strain PDT2.12
(Figures 2, 4). Interestingly, at the border of the missing region lies a Tn7-like element, which is present in all three plasmids. This putative $c a$. 7-kb transposon is reminiscent of a similar element found in strain ATCC 10987 of B. cereus, which was suggested to participate in the mobility of neighboring Genomic Islands (GI; Zhang and Zhang, 2008).

This plasmid trio is also distantly related to the conjugative plasmids pAW63 from B. thuringiensis sv. kurstaki HD73 and pBT9727 from B. thuringiensis sv. konkukian, and to the

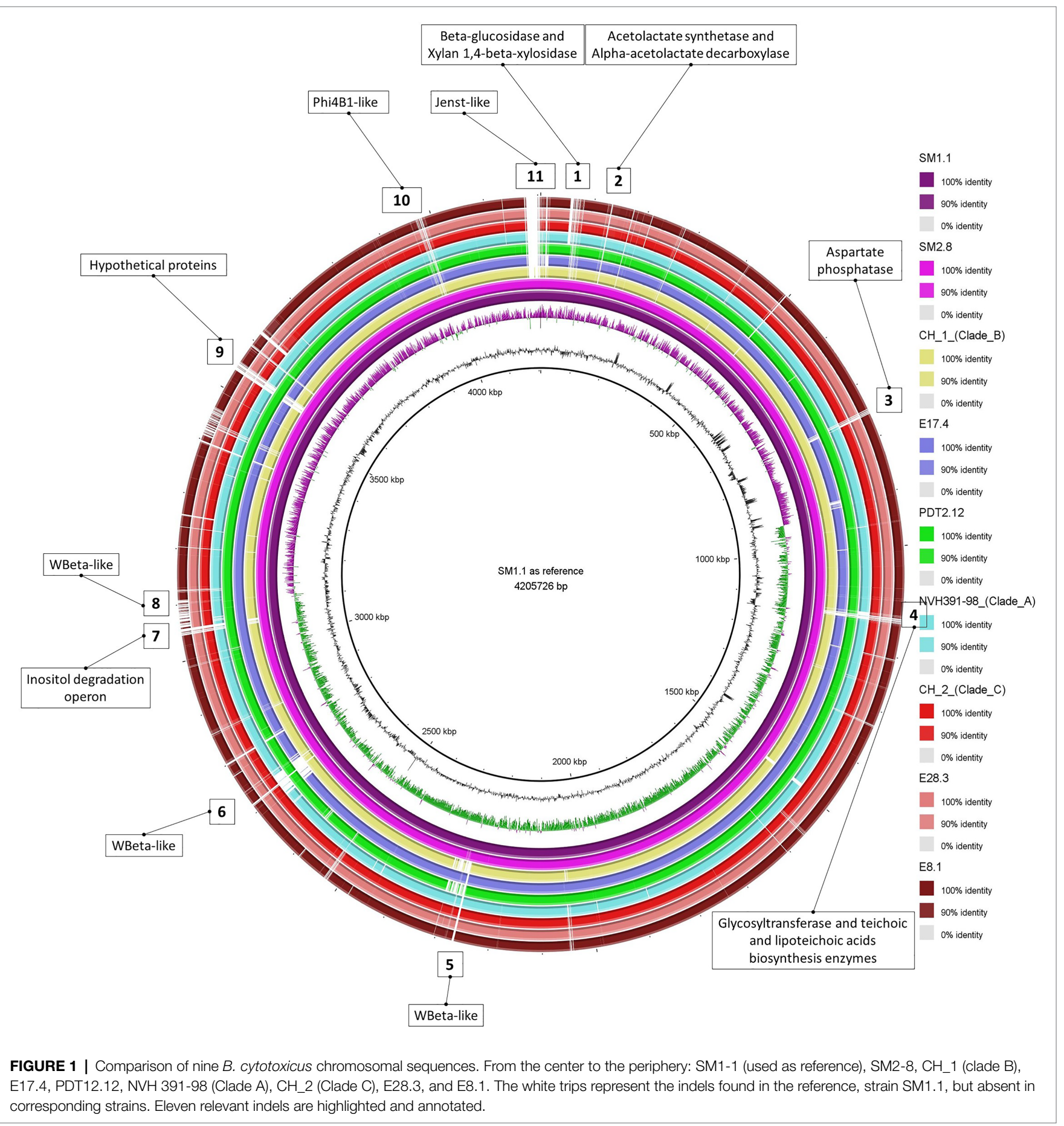




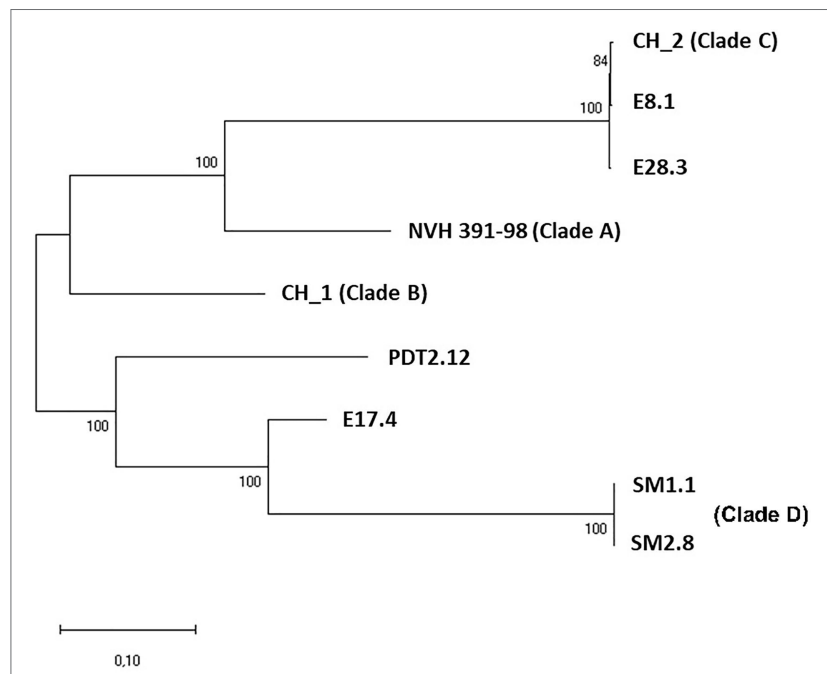

FIGURE 2 | Maximum Likelihood single nucleotide polymorphism (SNP) base-phylogenetic tree of the six sequenced $B$. cytotoxicus strains, along with representatives of genomic clades $\mathrm{A}$ (NVH 391-98), $\mathrm{B}\left(\mathrm{CH} \_1\right)$, and $\mathrm{C}\left(\mathrm{CH} \_2\right)$. Note that clade D also includes strain AFSSA_08CEB44bac. Percentage of corresponding bootstrap replicates shown at the base of each node.

conjugation-deficient pXO2 from B. anthracis (Wilcks et al., 1999; Van der Auwera et al., 2005, 2008; Figure 4). In addition, they are partially related to the $B$. cytotoxicus p67 plasmid (Figure 4) reported by Stevens et al. (2019). Yet, whereas pE81-84 and pE283-80 contain a Type IV Secretion System (T4SS) region potentially involved in conjugative transfer (Van der Auwera and Mahillon, 2008), both pPDT212-44 and p67 are lacking this region.

Strain E8.1 not only contains the potentially conjugative plasmid pE81-84, but also the 53,121 bp plasmid pE81-53, which displays a $c a$. 20-kb "conjugation-related" region. This segment contains several genes coding for putative conjugal transfer proteins, including a TcpE-like protein found in the conjugative plasmid pCW3 from Clostridium perfringens (Wisniewski et al., 2015). It is related to the 53-kb plasmid found in clades B and C of B. cytotoxicus strains (Stevens et al., 2019), as well as to plasmids pCE3 from Bacillus paranthracis strain BC307 (NZ_CP047088.1) and pBCM1301 from $B$. cereus strain M13 (NZ_CP016361.1; Figure 5). In order to assess the potential mobility of pE81-53, filter-mating conjugation experiments (Hinnekens et al., 2019) were carried out between a streptomycin-resistant mutant strain E8.1 (donor) and a rifampicin-resistant mutant of E17.4 (recipient). After mating, the presence of pE81-53 in the recipient strain was detected via PCR. The results indicated that pE81-53 could be transferred at a frequency of about $10^{-2}$ transconjugants per donor (T/D), which suggests that it is a bona fide conjugative element.

The last two large plasmids reside in strain SM1.1: pSM11-43 (43,118 bp) and pSM11-51 (51,478bp). With a query covering of $41 \%$ and an identity of $86 \%$, pSM11-51 is related to plasmid pBc53 (NC_011971.1) from B. cereus strain Q1 (Xiong et al., 2009). As indicated below, pSM11-43 and pSM11-51 contain

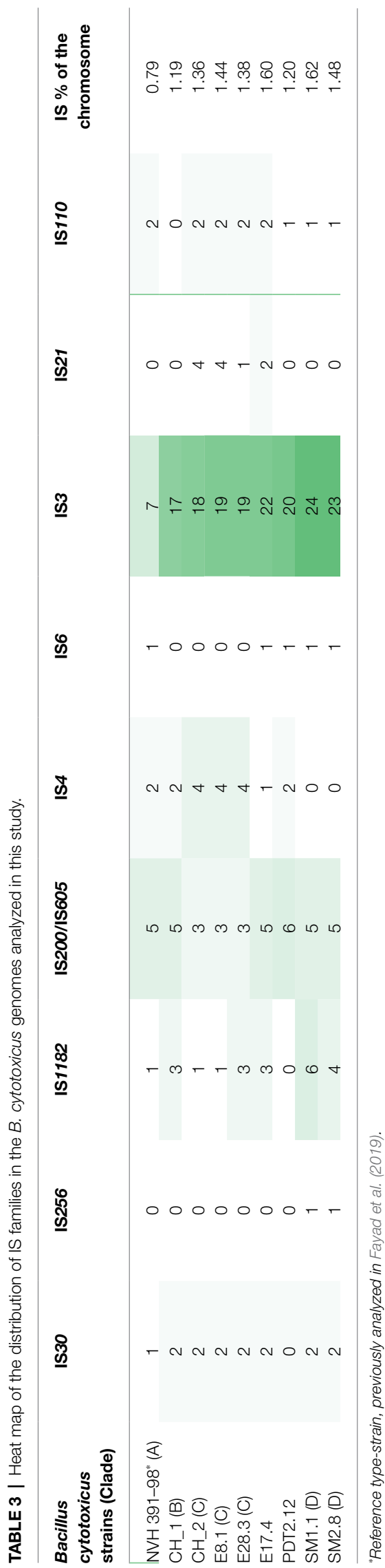




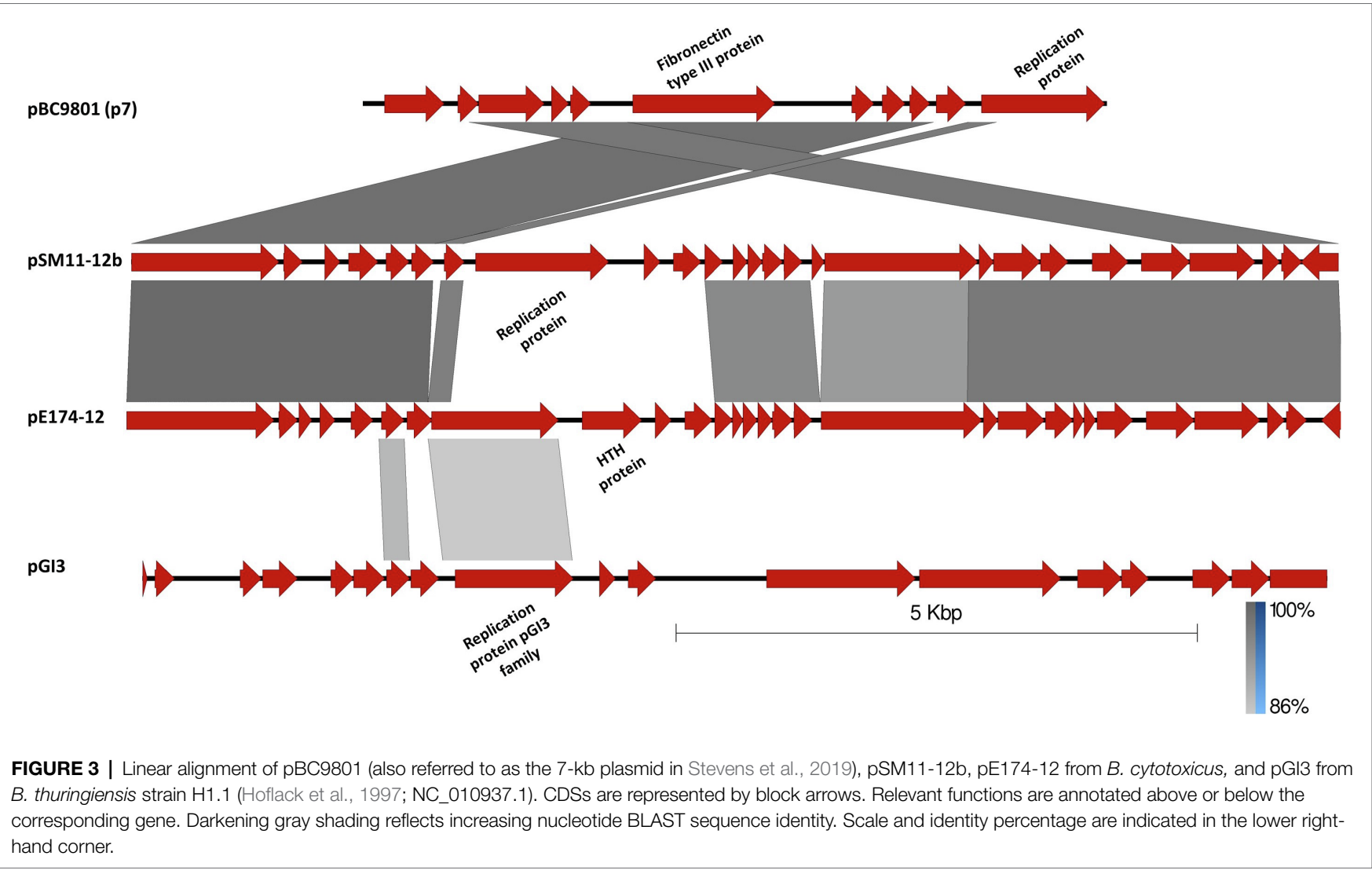

a significant proportion of their CDSs displaying homologies with those of Gram-positive prophages. Whether these elements are genuine plasmidial prophages or if they correspond to the insertion of prophages into resident plasmids remain to be tested.

\section{Other Mobile Genetic Elements Prophages}

PHAge Search Tool Enhanced Release was used to annotate phage-related proteins and to compare them to those available in the databases. A focus was granted to the six putative "intact" prophages detected in the strains. An average of 23 proteins related to the WBeta prophage, a siphovirus originally isolated from a B. anthracis strain (Schuch and Fischetti, 2006), were found on the chromosome of seven of the nine $B$. cytotoxicus strains. Potential Phi4B1-like elements (siphovirus from $B$. thuringiensis 4B1, NC028886) were also identified in eight of the nine strains, with the exception of E17.4. The CH_2 and E8.1 strains carry two copies of Phi4B1-like prophages, one "intact" with 22 and 23 related proteins and the second "partial" with only 13 Phi4B1-like proteins. Similarly, the number of identified Phi4B1-related proteins varied from 13 to 15 in E28.3, SM1.1, and SM2.8, respectively, suggesting the presence of "partial" Phi4B1-like element. Other potential prophages found on chromosomes are a Jenst-like prophage (siphovirus from Brevibacillus laterosporus; Merrill et al., 2015) only on SM1.1 chromosome, a GBSV1-like element (myovirus from Geobacillus sp.; Liu et al., 2009) only on $\mathrm{CH}_{-} 1$ chromosome, and a B025-like prophage (siphovirus from Listeria monocytogenes; Dorsch et al., 2009) only on SM2.8 chromosome.

As for plasmidial prophages, as indicated above, pE283-14 is a putative 14 -kb linear plasmidial prophage, similar to the tectiviral phages GIL01 and GIL16c isolated from $B$. thuringiensis (Verheust et al., 2005; Gillis and Mahillon, 2014a,b). A second potential plasmidial prophage is pSM11-43, the 43-kb extrachromosomal element of strain SM1.1. It is related to the $L$. monocytogenes siphovirus B025 (Dorsch et al., 2009). Interestingly, as reported above, this element is integrated in the chromosome of strain SM2.8. This is potentially due to its dual capacity to integrate the chromosome using a site-specific integration mechanism or to replicate as a circular plasmidial prophage. In fact, this prophage carries an integrase coding gene, as well as recombination sites. For the chromosomal B025-like, it is inserted within a helicase-coding gene on the chromosome. The prophage-like region is flanked by attL and attR sites, located on the left and right ends of the prophage, whereas pSM11-43 holds an attP-like site.

Finally, it is worth mentioning that in strain SM1.1, the Jenstlike potential prophage is located both on its chromosome and on pSM11-51, where it constitutes $c a$. $55 \%$ of this $51-\mathrm{kb}$ plasmid (Table 2). Within the chromosome, the Jenst-like prophage is inserted between a cation acetate symporter and a sodium/proline symporter PutP. Interestingly, Phi4J1, another siphovirus prophage from B. thuringiensis (NC029008), displayed similarities with the remainder region of pSM11-51, suggesting that this extrachromosomal element might also be a plasmidial prophage 


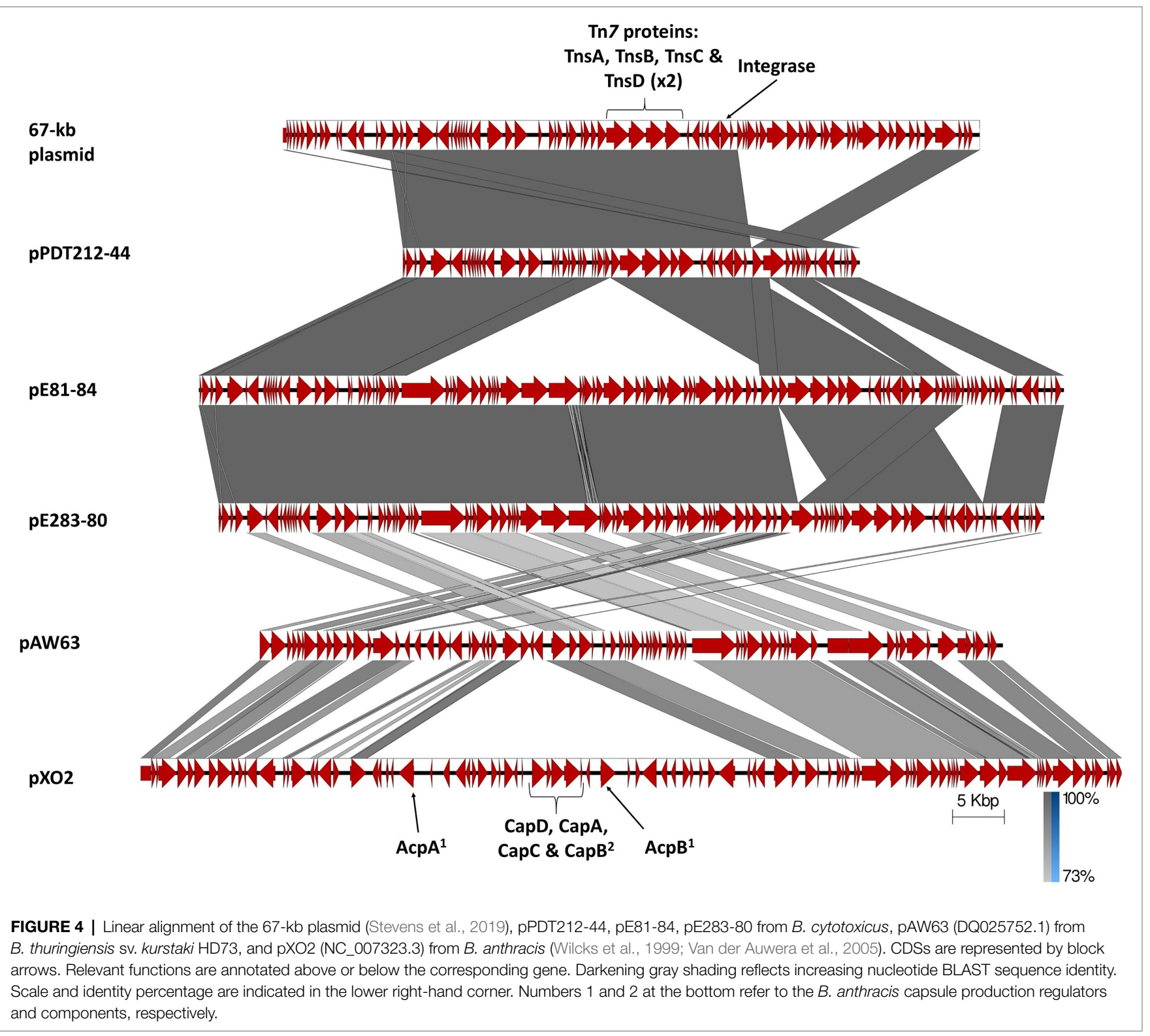

with distant relationship with both Jenst and Phi4J1 prophages. This plasmid also bares resemblance to the Bacillus phage BtS_ BMBtp3 (NC028748) first described in B. thuringiensis.

\section{Insertion Sequences, B. cereus Repeats, and Group II Introns}

Bacillus cytotoxicus is a member of B. cereus s.l., a group that has been shown to be rich in mobile genetic elements (Fayad et al., 2019). In this study, the sequenced isolates were mined for their IS elements, $b c r$, and group II introns. Using the ISsaga tool and a modified MegaBLASTn, IS and bcr elements and group II introns from newly sequenced isolates were compared to those of B. cytotoxicus strains NVH 391-98, CH_1, and $\mathrm{CH} \_2$ (genomic clades A, B, and C, respectively).

Elements belonging to nine IS families were found on the chromosomes, with no plasmidial IS elements recovered in the analyzed B. cytotoxicus genomes. As shown in Table 3, variations in the presence and copy number of IS families were observed. Out of the nine analyzed strains, (i) only SM1.1 and SM2.8 carry a copy of an IS256-like element and do not have an IS4 family element, (ii) PDT2.12 lacks IS30- and IS1182-like elements, (iii) $\mathrm{CH}_{-} 1$ does not carry an IS110 element; and (iv) NVH 391-98 displays a much lower copy number (seven) of IS3-like elements compared to the other strains (from 17 to 24). As for the percentage of the genome covered by IS elements, it ranged between $0.79 \%$ for $\mathrm{NVH}$ 391-98 and $1.62 \%$ for SM1.1.

Proteins related to the $\operatorname{Tn} 7$ transposon were found on the three related plasmids pPDT212-44, pE283-80, and pE81-84. The Tn7-encoded transposition genes $t n s A, B, C$, and $D$ (two copies) as well as an integrase-coding gene are located on these plasmids (Figure 4). TnsA and $\mathrm{B}$ are at the heart of the transposition 


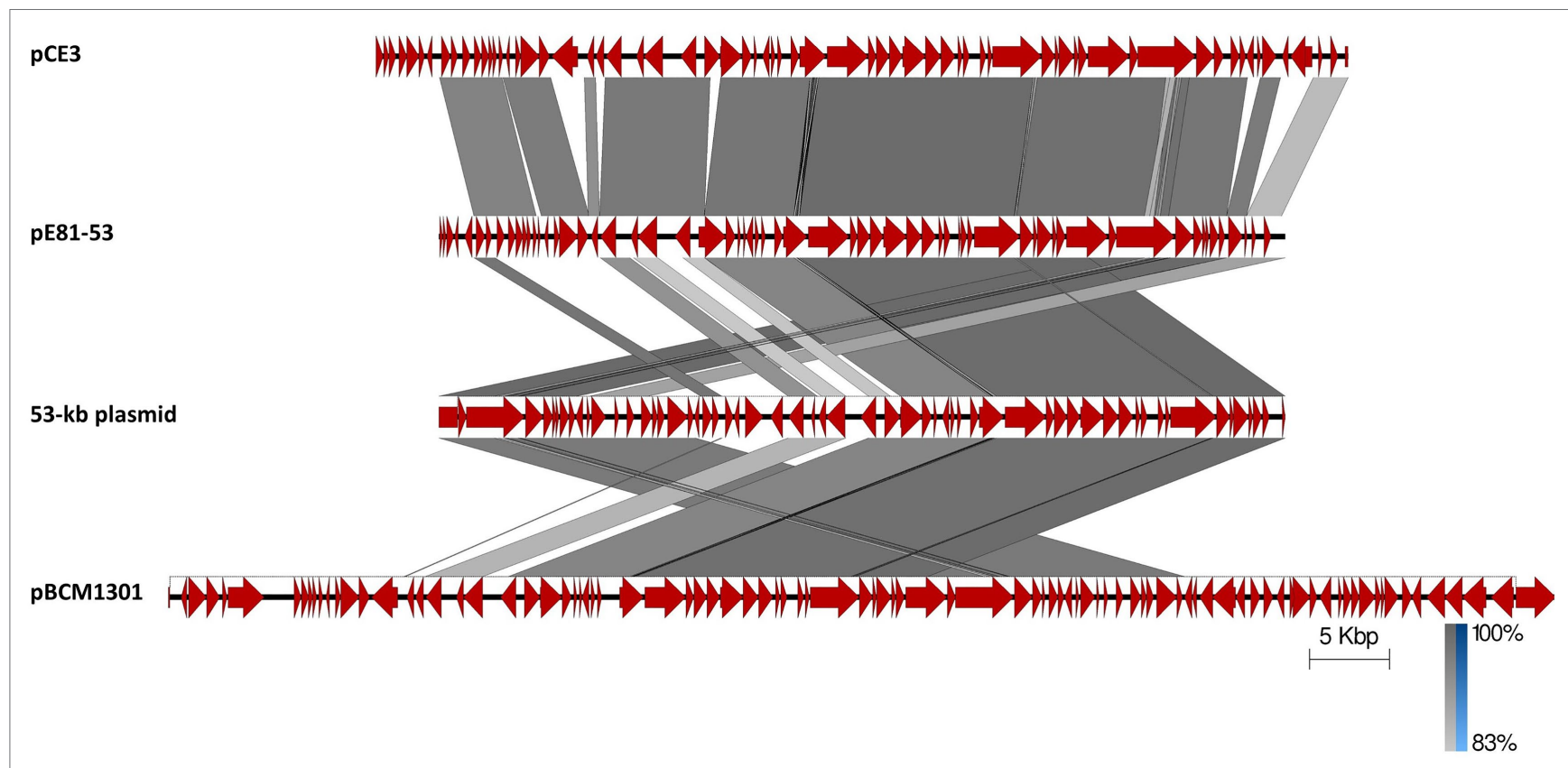

FIGURE 5 | Linear alignment of pCE3 from B. paranthracis strain BC307 (CP047088.1), pE81-53 and the 53-kb plasmid (Stevens et al., 2019) from B. cytotoxicus, and pBCM1301 from B. cereus strain M13 (CP016361.1). CDSs are represented by block arrows. Darkening gray shading reflects increasing nucleotide BLAST sequence identity. Scale and identity percentage are indicated in the lower right-hand corner.

machinery since they mediate DNA strand breakage and joining, whereas $\mathrm{TnsC}$ and $\mathrm{TnsD}$ are regulators of transposition, also implicated in recognizing specific integration sites attTn7 (Craig, 1996). As for the integrase, while its presence is not required for $\mathrm{Tn} 7$ transposition, it plays a key role in acquiring gene cassettes as passenger genes associated with this transposon.

Concerning the $b c r, 12$ of the 18 known elements were found in the analyzed B. cytotoxicus genomes. Their genomic distribution is very similar among the strains, with small differences being noted for bcr2 and bcr5 (Supplementary Figure S1). Bcrl presented the highest copy number, from 57 in strain NVH 391-98 to 63 in strains SM1.1 and SM2.8. Finally, only one complete copy of B.c.I8, a group II intron encoding a 543 amino acid IEP originally found in B. cytotoxicus strain NVH 391-98, was found in the genomes of all six isolates.

\section{DISCUSSION}

Although it has been demonstrated that B. cytotoxicus strains constituted a remote cluster from the other $B$. cereus group members (Fagerlund et al., 2007), recent studies have shown that isolates of this species displayed noticeable chromosomal and plasmidial diversities (Koné et al., 2019; Stevens et al., 2019). The first B. cytotoxicus strain was isolated during a severe foodborne outbreak in France that led to three fatalities. Nevertheless, present data on this species suggest a straindependent, variable cytotoxicity. Indeed, a recent study suggested that the cytotoxic and fatal potential of this species might be lower than initially thought (Burtscher et al., 2021).
The current study extends insight into this intra-species genetic and genomic diversity. As for the other B. cytotoxicus genomes publicly available (Stevens et al., 2019), the six new strains sequenced in this study have chromosome sizes ranging from 4.1 to $4.2 \mathrm{Mb}$. Also, their genomes contained up to $3.3 \%$ of plasmid DNA, with sizes ranging from 3.4 to almost $84 \mathrm{~kb}$. Compared to the four recently described clades (i.e., clades A-D, Stevens et al., 2019), two of our strains, E8.1 and E28.3, belong to clade C (Figure 2), that contained the majority of publicly available B. cytotoxicus genomes, while SM1.1 and SM2.8 pertain to clade D, together with strain AFSSA_08CEB44Bac (BioProject: PRJEB14962) isolated in France. The two remaining strains (i.e., PDT2.12 and E17.4) do not belong to previously described clades. This is in line with our recent study showing that these $B$. cytotoxicus isolates were the sole member of their RAPD patterns, while SM1.1 and SM2.8 displayed the same RAPD pattern (Koné et al., 2019), but differ by 13 chromosomal indels. Of note is the origin of these SM1.1 and SM2.8 strains that were isolated from two Moroccan soups: Harira and Chorba, respectively (Koné et al., 2019). However, it is worth mentioning that these instant soups contained potatoderived products as additives, which might be related to the presence of these bacteria.

Concerning the link between diversity and potential pathogenicity, it has been suggested that strains from clade A (which contains the original and reference type-strain $\mathrm{NVH}$ 391-98 and the highly cytotoxic CH_213) and from clade B were more likely to be cytotoxic compared to those of clades C and D (Stevens and Johler, 2020). However, the exact factor(s) and mechanism(s) responsible for the higher cytotoxicity 
displayed by these $B$. cytotoxicus strains remain(s) to be further explored.

The functional comparison showed that four out of six sequenced isolates (SM1.1, SM2.8, PDT2.12, and E17.4) possess enzymes implicated in the degradation of inositol, a polyalcohol mainly present in soil and plants. This catabolic operon has been found in environmental dwelling bacteria such as Bacillus subtilis or Klebsiella aerogenes (Yoshida et al., 2008).

As for other B. cereus group members, the B. cytotoxicus reference strain is not able to use galactose (Guinebretière et al., 2013), and analyses of publicly available sequences did not find any galactose degradation enzymatic pathway in their genomes. Surprisingly PDT2.12 contains sequences coding for galactose uptake and degradation enzymes. This hints that this isolate may have thrived in dairy environments and acquired these sequences from other galactose-using bacteria through horizontal gene transfer.

To avoid the taxonomic ambiguity of the B. cereus group, $B$. cytotoxicus genomes were searched for the presence of virulence genes typically used as markers for the entomopathogenic $B$. thuringiensis strains, i.e., those encoding crystal proteins or those toxic for insect larvae: the $\delta$-endotoxins $c r y$, cytolytic cyt, and the vegetative insecticidal protein coding genes vip. No entomopathogenic genes were found on the chromosomes or plasmids of the B. cytotoxicus strains.

More than a decade ago, the interest in phages preying on the $B$. cereus group was revived, bringing forth the questions about their diversity and potential implication in the ecology and adaptability of members of this group (Gillis and Mahillon, 2014a). While some have a lytic life cycle, others are lysogenic and can remain in a dormant state as prophages integrated into the chromosome, into plasmids or as circular/linear elements aka plasmidial prophages (Gillis and Mahillon, 2014a; Piligrimova et al., 2021). Prophages found in B. cereus s.s., B. anthracis, and $B$. thuringiensis strains have been extensively studied, thanks to the abundance of genomic sequences of these three species, in contrast to $B$. cytotoxicus genomes, still relatively new to the genomic field. In this study, the genomes of nine $B$. cytotoxicus strains were analyzed for the presence of prophages, via the online tool PHASTER. Six putative prophages were found to be "intact" on the chromosomes or plasmids. Interestingly, some prophages marked diverse regions on the chromosomes (regions 5, 6, 8, 10, and 11, Figure 1), making them a valuable addition to the bacteria's genetic pool. For chromosomal and plasmidial prophages, the question of their activity and potential for a lytic cycle is still unanswered and requires further investigation. Nonetheless, for the plasmidial prophages, an added value could be their potential for horizontal genetic transfer, hence their status as "mobilizable."

A special case is that of the prophage dubbed as B025-like, found as a plasmidial prophage in SM1.1, pSM11-43, and integrated in the chromosome of strain SM2.8. B025 originally isolated from a Listeria strain has the tools required for integration (att sequences and an integrase coding gene) and circularization (cohesive single-strand complementary cos ends). The capacity of a bacteriophage to exist in both integrated and excised forms was previously reported for a Streptococcus pyogenes M1 serotype phage SpyCIM1. The latter forms a chromosomal island integrated at a specific site of the chromosome, while the bacterium is in a stationary growth phase. However, once in exponential growth phase, SpyCIM1 excises from the chromosome and replicates as an independent plasmidial prophage (Nguyen and McShan, 2014; Utter et al., 2014). Another example is the circular plasmidial prophage pLUSID3, recently described in B. thuringiensis strain HER1410, which can also occur as fully integrated within the chromosome causing the disruption of a flagellar key component (Lechuga et al., 2020). Whether these B025-like elements are active or defective prophages and whether some are merely integrated into resident plasmids or are true plasmidial prophages will required further experiments.

Other mobile genetic elements were mined in the B. cytotoxicus genomes, including IS elements. Although no plasmidial IS were recovered, the variability of chromosomal IS elements between the different strains and clades was evident, with $\mathrm{NVH}$ 391-98 presenting the lowest number of IS. Surprisingly, 1.62\% of the chromosome of SM1.1 is covered by IS, the highest number for the nine strains, which is higher than the average $1.1 \%$ of $B$. thuringiensis, keeping in mind that for the latter species, IS prevalence and diversity are dominantly plasmidial (Fayad et al., 2019).

The plasmidome showed the greatest diversity among the six sequenced B. cytotoxicus strains, including four small plasmids and six large ones, whose prevalence and distribution are summarized in Table 4. While some plasmids were unique to a particular strain, e.g., the 3 - and $4-\mathrm{kb}$ plasmids of E28.3, others were more or less similar to plasmids carried by other strains. For the $12-\mathrm{kb}$ plasmids, one set (12a) is identical in SM1.1 and SM2.8, while the other (12b) is identical between SM1.1 and SM2.8 but is closely related to pE174-12 and the 7-kb pBC9801 element of the reference strain NVH 391-98. The main difference between the 7-kb, $12 \mathrm{~b}$, and pE174-12 plasmids is the replication protein (Figure 3). However, one of the main shared regions is encoding a Fibronectin type III domain-containing protein. This domain mediates protein-protein interaction and is potentially involved in the correct positioning of a protein's active domain (Campbell and Spitzfaden, 1994). Although its exact role remains unclear, it is often associated with enzymes involved in the degradation of recalcitrant polysaccharides such as chitin, as shown for the chitinase of B. thuringiensis (Juárez-Hernández et al., 2019).

The most prevalent plasmid, or plasmidial region, is pPDT21244 , to which similarities are found on five other plasmids, in five strains from two clades, and one not placed in a particular clade (Table 4; Figure 4). Finally, the 53 -kb conjugative plasmid pE81-53 shows similarities with the other 53-kb elements in previously reported $B$. cytotoxicus strains, implying their conjugative potential as well (Figure 5; Stevens et al., 2019). In total, the $53-\mathrm{kb}$ element was found in four strains from two different clades, B and C (Table 4).

Another quite interesting feature of the small plasmids is the presence on pSM11-12a of strain SM1.1 (as well as on strain SM2.8) of three genes highly similar to the gakABC 


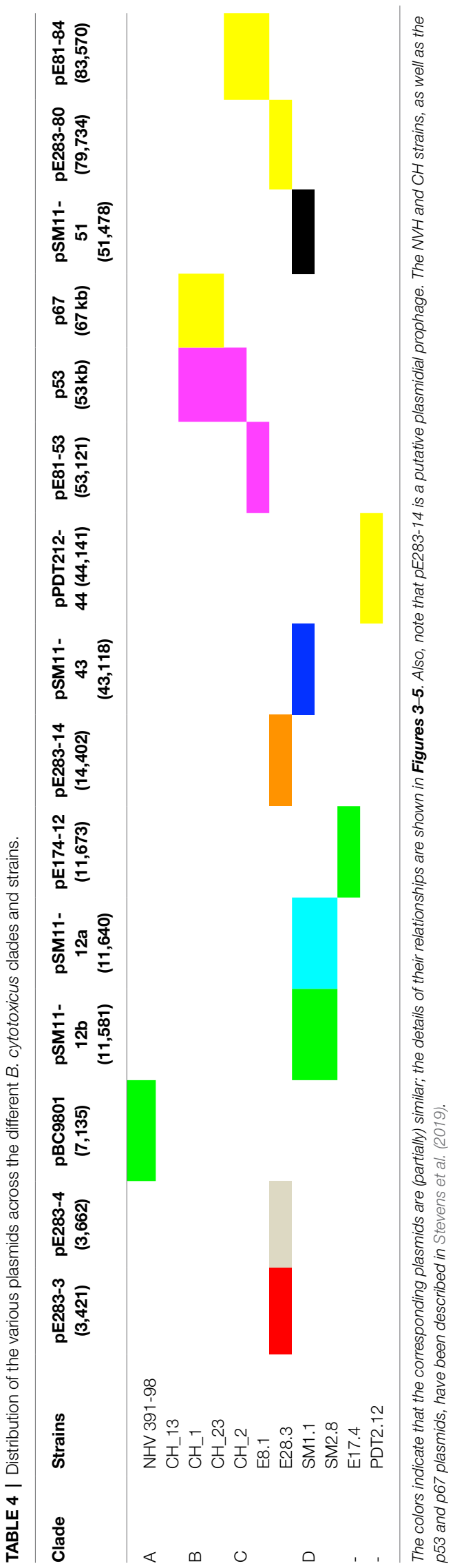

locus found in Lactococcus garvieae that code for the threepeptide bacteriocin Garvicin KS (Ovchinnikov et al., 2016). This bacteriocin and homologues found in B. cereus strains are active against several other Gram-positive bacteria including members of the Bacillus, Enterococcus, Listeria, and Streptococcus genera. Intriguingly, the homology extends outside this locus and includes neighboring genes such as putative $\mathrm{ABC}$ transporter and recombinase/integrase-like genes, suggesting they are part of a mobile genetic element. The activity of this Garvicin KS-like bacteriocin, also referred to as Cereucin in the case of the B. cereus strains (Ovchinnikov et al., 2016), on other bacteria is currently under investigation.

The aim of this study was to extend the understanding about the intra-species diversity of B. cytotoxicus through WGS and comparative genomic analyses of six isolates. The SNP-based phylo-dendrogram, as well as the ANI, showed that two isolates from instant soup fitted in the clade D, two from potato flakes were classified in clade $\mathrm{C}$, and the last two, also from potato flakes, formed a separated cluster from the other clades. The plasmidial diversity is also in line with previous studies. The presence of sequences coding for inositol degradation in four isolates genomes and galactose uptake and degradation enzymes hinted the ecological niche of B. cytotoxicus. Nevertheless, in order to extend the insight on knowledge about the genetic diversity of B. cytotoxicus and its ecological niche, there is a need to sequence and study more isolates from matrices other than potato products.

\section{DATA AVAILABILITY STATEMENT}

The datasets presented in this study can be found in online repositories. The names of the repository/repositories and accession number(s) can be found at: https://www.ncbi.nlm. nih.gov/, PRJNA684687.

\section{AUTHOR CONTRIBUTIONS}

KK, NF, AG, and JM contributed to conceptualization, validation, methodology, and writing - review and editing. KK, AG, and NF provided software and were involved in investigation. KK, NF, and JM contributed to formal analysis, data curation, writing - original draft preparation, and visualization. JM was involved in resources, supervision, project administration, and funding. All authors contributed to the article and approved the submitted version.

\section{FUNDING}

This work was supported by the International Office for Cooperation of the Université catholique de Louvain (UCLouvain; Bursaries to KK and NF), the Research Department of the Communauté française de Belgique (Concerted Research Action, 
ARC 17/22-084), and the National Fund for Scientific Research (FNRS, Belgium; research grant FNRS-CDR J.0144.20 to JM and research position FNRS 1.B208.16 to AG).

\section{ACKNOWLEDGMENTS}

We thank A. Hennevaux de Fécher for her help in performing the plasmid experiments and sharing discussion on this

\section{REFERENCES}

Agata, N., Mori, M., Ohta, M., Suwan, S., Ohtani, I., and Isobe, M. (1994). A novel dodecadepsipeptide, cereulide, isolated from Bacillus cereus causes vacuole formation in HEp-2 cells. FEMS Microbiol. Lett. 121, 31-34. doi: 10.1111/j.1574-6968.1994.tb07071.x

Agata, N., Ohta, M., Mori, M., and Isobe, M. (1995). A novel dodecadepsipeptide, cereulide, is an emetic toxin of Bacillus cereus. FEMS Microbiol. Lett. 129, 17-20. doi: 10.1016/0378-1097(95)00119-P

Alikhan, N. F., Petty, N. K., Ben Zakour, N. L., and Beatson, S. A. (2011). BLAST ring image generator (BRIG): simple prokaryote genome comparisons. BMC Genomics 12:402. doi: 10.1186/1471-2164-12-402

Antipov, D., Korobeynikov, A., McLean, J. S., and Pevzner, P. A. (2015). hybridSPAdes: an algorithm for hybrid assembly of short and long reads. Bioinformatics 32, 1009-1015. doi: 10.1093/bioinformatics/btv688

Arndt, D., Grant, J. R., Marcu, A., Sajed, T., Pon, A., Liang, Y., et al. (2016). PHASTER: a better, faster version of the PHAST phage search tool. Nucleic Acids Res. 44, W16-W21. doi: 10.1093/nar/gkw387

Auger, S., Galleron, N., Bidnenko, E., Ehrlich, S. D., Lapidus, A., and Sorokin, A. (2008). The genetically remote pathogenic strain NVH 391-98 of the Bacillus cereus group is representative of a cluster of thermophilic strains. Appl. Environ. Microbiol. 74, 1276-1280. doi: 10.1128/AEM.02242-07

Aziz, R. K., Bartels, D., Best, A. A., DeJongh, M., Disz, T., Edwards, R. A., et al. (2008). The RAST server: rapid annotations using subsystems technology. BMC Genomics 9:75. doi: 10.1186/1471-2164-9-75

Bankevich, A., Nurk, S., Antipov, D., Gurevich, A. A., Dvorkin, M., Kulikov, A. S., et al. (2012). SPAdes: a new genome assembly algorithm and its applications to single-cell sequencing. J. Comput. Biol. 19, 455-477. doi: 10.1089/ cmb.2012.0021

Bazinet, A. L. (2017). Pan-genome and phylogeny of bacillus cereus sensu lato. BMC Evol. Biol. 17:176. doi: 10.1186/s12862-017-1020-1

Blin, K., Shaw, S., Steinke, K., Villebro, R., Ziemert, N., Lee, S. Y., et al. (2019). AntiSMASH 5.0: updates to the secondary metabolite genome mining pipeline. Nucleic Acids Res. 47, W81-W87. doi: 10.1093/nar/gkz310

Boe, L., Nielsen, T. T., Madsen, S. M., Andrup, L., and Bolander, G. (1991). Cloning and characterization of two plasmids from bacillus thuringiensis in Bacillus subtilis. Plasmid 25, 190-197. doi: 10.1016/0147-619X(91)90012-L

Burtscher, J., Etter, D., Biggel, M., Schlaepfer, J., and Johler, S. (2021). Further insights into the toxicity of bacillus cytotoxicus based on toxin gene profiling and Vero cell cytotoxicity assays. Toxins 13:234. doi: 10.3390/toxins13040234

Camacho, C., Coulouris, G., Avagyan, V., Ma, N., Papadopoulos, J., Bealer, K., et al. (2009). BLAST+: architecture and applications. BMC Bioinformatics 10:421. doi: 10.1186/1471-2105-10-421

Campbell, I. D., and Spitzfaden, C. (1994). Building proteins with fibronectin type III modules. Structure 2, 333-337. doi: 10.1016/S0969-2126(00)00034-4

Candales, M. A., Duong, A., Hood, K. S., Li, T., Neufeld, R. A. E., Sun, R., et al. (2011). Database for bacterial group II introns. Nucleic Acids Res. 40, D187-D190. doi: 10.1093/nar/gkr1043

Caulier, S., Nannan, C., Gillis, A., Licciardi, F., Bragard, C., and Mahillon, J. (2019). Overview of the antimicrobial compounds produced by members of the Bacillus subtilis group. Front. Microbiol. 10:302. doi: 10.3389/ fmicb.2019.00302

Cavello, I., Urbieta, M. S., Cavalitto, S., and Donati, E. (2020). Bacillus cytotoxicus isolated from a pristine natural geothermal area reveals high keratinolytic activity. Microorganisms 8:796. doi: 10.3390/microorganisms 8060796 manuscript. We also thank C. Michaux for her help and advices throughout this work.

\section{SUPPLEMENTARY MATERIAL}

The Supplementary Material for this article can be found online at: https://www.frontiersin.org/articles/10.3389/fmicb.2021.789929/ full\#supplementary-material

Craig, N. L. (1996). “Transposon Tn7,” in Transposable Elements: Current Topics in Microbiology and Immunology. Vol. 204. eds. H. Saedler and A. Gierl (Berlin, Heidelberg: Springer).

Darling, A. E., Mau, B., and Perna, N. T. (2010). ProgressiveMauve: multiple genome alignment with gene gain, loss and rearrangement. PLoS One 5:e11147. doi: 10.1371/journal.pone.0011147

Dorsch, J., Klumpp, J., Bielmann, R., Schmelcher, M., Born, Y., Zimmer, M., et al. (2009). Comparative genome analysis of listeria bacteriophages reveals extensive mosaicism, programmed translational frameshifting, and a novel prophage insertion site. J. Bacteriol. 191, 7206-7215. doi: 10.1128/JB.01041-09

Ehling-Schulz, M., Fricker, M., and Scherer, S. (2004). Bacillus cereus, the causative agent of an emetic type of foodborne illness. Mol. Nutr. Food Res. 48, 479-487. doi: 10.1002/mnfr.200400055

Fagerlund, A., Brillard, J., Fürst, R., Guinebretière, M.-H., and Granum, P. E. (2007). Toxin production in a rare and genetically remote cluster of strains of the Bacillus cereus group. BMC Microbiol. 7:43. doi: 10.1186/1471-2180-7-43

Fagerlund, A., Ween, O., Lund, T., Hardy, S. P., and Granum, P. E. (2004). Genetic and functional analysis of the cytK family of genes in Bacillus cereus. Microbiology 150, 2689-2697. doi: 10.1099/mic.0.26975-0

Fayad, N., Kallassy Awad, M., and Mahillon, J. (2019). Diversity of Bacillus cereus sensu lato mobilome. BMC Genomics 20:436. doi: 10.1186/ s12864-019-5764-4

Gillis, A., Fayad, N., Makart, L., Bolotin, A., Sorokin, A., Kallassy, M., et al. (2018). Role of plasmid plasticity and mobile genetic elements in the entomopathogen bacillus thuringiensis serovar israelensis. FEMS Microbiol. Rev. 42, 829-856. doi: 10.1093/femsre/fuy034

Gillis, A., and Mahillon, J. (2014a). Phages preying on bacillus anthracis, Bacillus cereus, and bacillus thuringiensis: past, present and future. Viruses 6, 2623-2672. doi: 10.3390/v6072623

Gillis, A., and Mahillon, J. (2014b). Prevalence, genetic diversity, and host range of tectiviruses among members of the Bacillus cereus group. Appl. Environ. Microbiol. 80, 4138-4152. doi: 10.1128/AEM.00912-14

Granum, P. E. (1994). Bacillus cereus and its toxins. Soc. Appl. Bacteriol. Symp. Ser. 23, 61S-66S. doi: 10.1111/j.1365-2672.1994.tb04358.x

Guinebretière, M. H., Auger, S., Galleron, N., Contzen, M., De Sarrau, B., De Buyser, M.-L., et al. (2013). Bacillus cytotoxicus sp. nov. is a novel thermotolerant species of the Bacillus cereus group occasionally associated with food poisoning. Int. J. Syst. Evol. Microbiol. 63, 31-40. doi: 10.1099/ ijs.0.030627-0

Guinebretière, M. H., Thompson, F. L., Sorokin, A., Normand, P., Dawyndt, P., Ehling-Schulz, M., et al. (2008). Ecological diversification in the Bacillus cereus group. Environ. Microbiol. 10, 851-865. doi: 10.1111/j.1462-2920.2007.01495.x

Heini, N., Stephan, R., Ehling-Schulz, M., and Johler, S. (2018). Characterization of Bacillus cereus group isolates from powdered food products. Int. J. Food Microbiol. 283, 59-64. doi: 10.1016/j.ijfoodmicro.2018.06.019

Hinnekens, P., Koné, K. M., Fayad, N., Leprince, A., and Mahillon, J. (2019). pXO16, the large conjugative plasmid from bacillus thuringiensis serovar israelensis displays an extended host spectrum. Plasmid 102, 46-50. doi: 10.1016/j.plasmid.2019.02.004

Hoflack, L., Seurinck, J., and Mahillon, J. (1997). Nucleotide sequence and characterization of the cryptic bacillus thuringiensis plasmid pGI3 reveal a new family of rolling circle replicons. J. Bacteriol. 179, 5000-5008. doi: 10.1128/jb.179.16.5000-5008.1997

Hoton, F., Andrup, L., Swiecicka, I., and Mahillon, J. (2005). The cereulide 
genetic determinants of emetic Bacillus cereus are plasmid-borne. Microbiology 151, 2121-2124. doi: 10.1099/mic.0.28069-0

Jimenez, G., Urdiain, M., Cifuentes, A., Lopez-Lopez, A., Blanch, A. R., Tamames, J., et al. (2013). Description of bacillus toyonensis sp. nov., a novel species of the Bacillus cereus group, and pairwise genome comparisons of the species of the group by means of ANI calculations. Syst. Appl. Microbiol. 36, 383-391. doi: 10.1016/j.syapm.2013.04.008

Juárez-Hernández, E. O., Casados-Vázquez, L. E., Brieba, L. G., Torres-Larios, A., Jimenez-Sandoval, P., and Barboza-Corona, J. E. (2019). The crystal structure of the chitinase ChiA74 of bacillus thuringiensis has a multidomain assembly. Sci. Rep. 9:2591. doi: 10.1038/s41598-019-39464-z

Jung, M. Y., Kim, J.-S., Paek, W. K., Lim, J., Lee, H., Kim, P. II, et al. (2011). Bacillus manliponensis sp. nov., a new member of the Bacillus cereus group isolated from foreshore tidal flat sediment. J. Microbiol. 49, 1027-1032. doi: 10.1007/s12275-011-1049-6

Jung, M. Y., Paek, W. K., Park, I. S., Han, J. R., Sin, Y., Paek, J., et al. (2010). Bacillus gaemokensis sp. nov., isolated from foreshore tidal flat sediment from the Yellow Sea. J. Microbiol. 48, 867-871. doi: 10.1007/s12275-010-0148-0

Kaas, R. S., Leekitcharoenphon, P., Aarestrup, F. M., and Lund, O. (2014). Solving the problem of comparing whole bacterial genomes across different sequencing platforms. PLoS One 9:e104984. doi: 10.1371/journal.pone.0104984

Kolmogorov, M., Yuan, J., Lin, Y., and Pevzner, P. A. (2019). Assembly of long, error-prone reads using repeat graphs. Nat. Biotechnol. 37, 540-546. doi: 10.1038/s41587-019-0072-8

Koné, K. M., Douamba, Z., Halleux, M., Bougoudogo, F., and Mahillon, J. (2019). Prevalence and diversity of the thermotolerant bacterium bacillus cytotoxicus among dried food products. J. Food Prot. 82, 1210-1216. doi: 10.4315/0362-028X.JFP-19-006

Kristoffersen, S. M., Tourasse, N. J., Kolstø, A. B., and Økstad, O. A. (2011). Interspersed DNA repeats bcr1-bcr18 of Bacillus cereus group bacteria form three distinct groups with different evolutionary and functional patterns. Mol. Biol. Evol. 28, 963-983. doi: 10.1093/molbev/msq269

Kumar, S., Stecher, G., Li, M., Knyaz, C., and Tamura, K. (2018). MEGA X: molecular evolutionary genetics analysis across computing platforms. Mol. Biol. Evol. 35, 1547-1549. doi: 10.1093/molbev/msy096

Laing, C., Buchanan, C., Taboada, E. N., Zhang, Y., Kropinski, A., Villegas, A., et al. (2010). Pan-genome sequence analysis using Panseq: an online tool for the rapid analysis of core and accessory genomic regions. BMC Bioinformatics 11:461. doi: 10.1186/1471-2105-11-461

Lampson, B. C., and Parisi, J. T. (1986). Nucleotide sequence of the constitutive macrolide-lincosamide-streptogramin B resistance plasmid pNE131 from Staphylococcus epidermidis and homologies with Staphylococcus aureus plasmids pE194 and pSN2. J. Bacteriol. 167, 888-892. doi: 10.1128/jb.167.3.888-892.1986

Lapidus, A., Goltsman, E., Auger, S., Galleron, N., Ségurens, B., Dossat, C., et al. (2008). Extending the Bacillus cereus group genomics to putative food-borne pathogens of different toxicity. Chem. Biol. Interact. 171, 236-249. doi: 10.1016/j.cbi.2007.03.003

Lechuga, A., Lood, C., Salas, M., van Noort, V., Lavigne, R., and Redrejo-Rodriguez, M. (2020). Completed genomic sequence of bacillus thuringiensis HER1410 reveals a cry-containing chromosome, two megaplasmids, and an integrative plasmidial prophage. G3 10, 2927-2939. doi: $10.1534 / g 3.120 .401361$

Liu, B., Liu, G.-H., Hu, G.-P., Sengonca, C., Lin, N.-Q., Tang, J.-Y., et al. (2014). Bacillus bingmayongensis sp. nov., isolated from the pit soil of emperor Qin's Terra-cotta warriors in China. Antonie Van Leeuwenhoek 105, 501-510. doi: 10.1007/s10482-013-0102-3

Liu, B., Zhou, F., Wu, S., Xu, Y., and Zhang, X. (2009). Genomic and proteomic characterization of a thermophilic Geobacillus bacteriophage GBSV1. Res. Microbiol. 160, 166-171. doi: 10.1016/j.resmic.2008.12.005

Lund, T., De Buyser, M. L., and Granum, P. E. (2000). A new cytotoxin from Bacillus cereus that may cause necrotic enteritis. Mol. Microbiol. 38, 254-261. doi: 10.1046/j.1365-2958.2000.02147.x

Merrill, B. D., Berg, J. A., Graves, K. A., Ward, A. T., Hilton, J. A., Wake, B. N., et al. (2015). Genome sequences of five additional Brevibacillus laterosporus bacteriophages. Genome Announc. 3, e01146-e01115. doi: 10.1128/ genomeA.01146-15

Miller, R. A., Beno, S. M., Kent, D. J., Carroll, L. M., Martin, N. H., Boor, K. J., et al. (2016). Bacillus wiedmannii sp. nov., a psychrotolerant and cytotoxic
Bacillus cereus group species isolated from dairy foods and dairy environments. Int. J. Syst. Evol. Microbiol. 66, 4744-4753. doi: 10.1099/ijsem.0.001421

Morgulis, A., Coulouris, G., Raytselis, Y., Madden, T. L., Agarwala, R., and Schäffer, A. A. (2008). Database indexing for production MegaBLAST searches. Bioinformatics 24, 1757-1764. doi: 10.1093/bioinformatics/btn322

Nguyen, S. V., and McShan, W. M. (2014). Chromosomal islands of streptococcus pyogenes and related streptococci: molecular switches for survival and virulence. Front. Cell. Infect. Microbiol. 4:109. doi: 10.3389/fcimb.2014.00109

Ovchinnikov, K. V., Chi, H., Mehmeti, I., Holo, H., Nes, I. F., and Diep, D. B. (2016). Group of leaderless multipeptide bacteriocins from gram-positive bacteria. Appl. Environ. Microbiol. 82, 5216-5224. doi: 10.1128/AEM.01094-16

Piligrimova, E. G., Kazantseva, O. A., Kazantsev, A. N., Nikulin, N. A., Skorynina, A. V., Koposova, O. N., et al. (2021). Putative plasmid prophages of Bacillus cereus sensu lato may hold the key to undiscovered phage diversity. Sci. Rep. 11:7611. doi: 10.1038/s41598-021-87111-3

Richter, M., Rosselló-Móra, R., Oliver Glöckner, F., and Peplies, J. (2016). JSpeciesWS: A web server for prokaryotic species circumscription based on pairwise genome comparison. Bioinformatics 32, 929-931. doi: 10.1093/ bioinformatics/btv681

Schuch, R., and Fischetti, V. A. (2006). Detailed genomic analysis of the Wbeta and gamma phages infecting bacillus anthracis: implications for evolution of environmental fitness and antibiotic resistance. J. Bacteriol. 188, 3037-3051. doi: 10.1128/JB.188.8.3037-3051.2006

Senesi, S., and Ghelardi, E. (2010). Production, secretion and biological activity of Bacillus cereus enterotoxins. Toxins 2, 1690-1703. doi: 10.3390/toxins2071690

Seppey, M., Manni, M., and Zdobnov, E. M. (2019). BUSCO: assessing genome assembly and annotation completeness. Methods Mol. Biol. 1962, 227-245. doi: 10.1007/978-1-4939-9173-0_14

Stenfors Arnesen, L. P., Fagerlund, A., and Granum, P. E. (2008). From soil to gut: Bacillus cereus and its food poisoning toxins. FEMS Microbiol. Rev. 32, 579-606. doi: 10.1111/j.1574-6976.2008.00112.x

Stevens, M. J. A., and Johler, S. (2020). Draft genome sequence of CH_213, a highly cytotoxic bacillus cytotoxicus strain isolated from mashed potatoes. Microbiol. Resour. Announc. 9, e00836-e00820. doi: 10.1128/MRA.00836-20

Stevens, M. J. A., Tasara, T., Klumpp, J., Stephan, R., Ehling-Schulz, M., and Johler, S. (2019). Whole-genome-based phylogeny of bacillus cytotoxicus reveals different clades within the species and provides clues on ecology and evolution. Sci. Rep. 9:1984. doi: 10.1038/s41598-018-36254-x

Sullivan, M. J., Petty, N. K., and Beatson, S. A. (2011). Easyfig: a genome comparison visualizer. Bioinformatics 27, 1009-1110. doi: 10.1093/ bioinformatics/btr039

Sur, S., Romo, T. D., and Grossfield, A. (2018). Selectivity and mechanism of fengycin, an antimicrobial lipopeptide, from molecular dynamics. J. Phys. Chem. 122, 2219-2226. doi: 10.1021/acs.jpcb.7b11889

Tourasse, N. J., Helgason, E., Økstad, O. A., Hegna, I. K., and Kolstø, A. B. (2006). The Bacillus cereus group: novel aspects of population structure and genome dynamics. J. Appl. Microbiol. 101, 579-593. doi: 10.1111/j.1365-2672.2006.03087.x

Tourasse, N. J., and Kolstø, A.-B. (2008). Survey of group I and group II introns in 29 sequenced genomes of the Bacillus cereus group: insights into their spread and evolution. Nucleic Acids Res. 36, 4529-4548. doi: 10.1093/ nar/gkn372

Turnbull, P. C. (1999). Definitive identification of bacillus anthracis - a review. J. Appl. Microbiol. 87, 237-240. doi: 10.1046/j.1365-2672.1999.00876.x

Utter, B., Deutsch, D. R., Schuch, R., Winer, B. Y., Verratti, K., Bishop-Lilly, K., et al. (2014). Beyond the chromosome: the prevalence of unique extrachromosomal bacteriophages with integrated virulence genes in pathogenic Staphylococcus aureus. PLoS One 9:e100502. doi: 10.1371/journal.pone.0100502

Van der Auwera, G. A., Andrup, L., and Mahillon, J. (2005). Conjugative plasmid pAW63 brings new insights into the genesis of the bacillus anthracis virulence plasmid pXO2 and of the bacillus thuringiensis plasmid pBT9727. BMC Genomics 6:103. doi: 10.1186/1471-2164-6-103

Van der Auwera, G. A., and Mahillon, J. (2008). Transcriptional analysis of the conjugative plasmid pAW63 from bacillus thuringiensis. Plasmid 60, 190-199. doi: 10.1016/j.plasmid.2008.07.003

Van der Auwera, G. A., Timmery, S., and Mahillon, J. (2008). Self-transfer and mobilisation capabilities of the pXO2-like plasmid pBT9727 from bacillus thuringiensis subsp. konkukian 97-27. Plasmid 59, 134-138. doi: 10.1016/j. plasmid.2007.11.007 
Varani, A. M., Siguier, P., Gourbeyre, E., Charneau, V., and Chandler, M. (2011). ISsaga is an ensemble of web-based methods for high throughput identification and semi-automatic annotation of insertion sequences in prokaryotic genomes. Genome Biol. 12:R30. doi: 10.1186/gb-2011-12-3-r30

Verheust, C., Fornelos, N., and Mahillon, J. (2005). GIL16, a new gram-positive tectiviral phage related to the bacillus thuringiensis GIL01 and the Bacillus cereus pBClin15 elements. J. Bacteriol. 187, 1966-1973. doi: 10.1128/ JB.187.6.1966-1973.2005

Wilcks, A., Smidt, L., Økstad, O. A., Kolstø, A.-B., Mahillon, J., and Andrup, L. (1999). Replication mechanism and sequence analysis of the replicon of pAW63, a conjugative plasmid from Bacillus thuringiensis. J. Bacteriol. 181, 3193-3200. doi: 10.1128/JB.181.10.3193-3200.1999

Wisniewski, J. A., Teng, W. L., Bannam, T. L., and Rood, J. I. (2015). Two novel membrane proteins, TcpD and TcpE, are essential for conjugative transfer of pCW3 in Clostridium perfringens. J. Bacteriol. 197, 774-781. doi: 10.1128/JB.02466-14

Xiong, Z., Jiang, Y., Qi, D., Lu, H., Yang, F., Yang, J., et al. (2009). Complete genome sequence of the extremophilic Bacillus cereus strain Q1 with industrial applications. J. Bacteriol. 191, 1120-1121. doi: 10.1128/JB.01629-08

Yoshida, K.-I., Yamaguchi, M., Morinaga, T., Kinehara, M., Ikeuchi, M., Ashida, H., et al. (2008). Myo-inositol catabolism in Bacillus subtilis. J. Biol. Chem. 283, 10415-10424. doi: 10.1074/jbc.M708043200
Zhang, R., and Zhang, C. T. (2008). Accurate localization of the integration sites of two genomic islands at single-nucleotide resolution in the genome of Bacillus cereus ATCC 10987. Comp. Funct. Genomics 2008:451930. doi: $10.1155 / 2008 / 451930$

Conflict of Interest: The authors declare that the research was conducted in the absence of any commercial or financial relationships that could be construed as a potential conflict of interest.

Publisher's Note: All claims expressed in this article are solely those of the authors and do not necessarily represent those of their affiliated organizations, or those of the publisher, the editors and the reviewers. Any product that may be evaluated in this article, or claim that may be made by its manufacturer, is not guaranteed or endorsed by the publisher.

Copyright (C) 2021 Fayad, Koné, Gillis and Mahillon. This is an open-access article distributed under the terms of the Creative Commons Attribution License (CC BY). The use, distribution or reproduction in other forums is permitted, provided the original author(s) and the copyright owner(s) are credited and that the original publication in this journal is cited, in accordance with accepted academic practice. No use, distribution or reproduction is permitted which does not comply with these terms. 